\title{
Avanços na pesquisa com plantas forrageiras tropicais em pastagens: características morfofisiológicas e manejo do pastejo
}

\author{
Sila Carneiro da Silva ${ }^{1}$, Domicio do Nascimento Júnior ${ }^{2}$
}

\author{
${ }^{I}$ Professor Associado do Departamento de Zootecnia da ESALQ/USP, Piracicaba, SP, e pesquisador do CNPq. e-mail: \\ scdsimlva@esalq.usp.br. \\ ${ }^{2}$ Professor Titular do Departamento de Zootecnia da UFV, Viçosa, MG, e pesquisador do CNPq.
}

RESUMO - O manejo do pastejo tem sido uma preocupação constante da pesquisa com plantas forrageiras no Brasil há muitos anos. No entanto, foi durante a última década que ocorreram grandes mudanças e um avanço significativo na compreensão de fatos e processos determinantes da correta utilização das plantas forrageiras tropicais em pastagens. $\mathrm{O}$ presente texto tem por objetivo traçar um breve histórico da pesquisa com plantas forrageiras e pastagens no país, apontando sua evolução, tendências, resultados e épocas de transição. Isso colocará o conhecimento disponível em perspectiva e servirá de base para a discussão da importância e relevância dos estudos envolvendo avaliações das características morfofisiológicas das plantas forrageiras para fins de planejamento e definição de estratégias de manejo do pastejo. As informações são apresentadas de maneira sistematizada, favorecendo uma visão integrada das diferentes tendências e concepções filosóficas da pesquisa com plantas forrageiras no país, apontando, de maneira crítica, a necessidade de revisão e mudança de paradigmas como forma de promover a melhoria, aperfeiçoamento e o crescimento do conhecimento acerca da produção animal em pastagens.

Palavras-chave: ecofisiologia de plantas forrageiras, manejo do pastejo, morfogênese

SUMMARY - Grazing management has been the focus of the research with forage plants in Brazil for many years. However, it was during the last decade that significant changes and advance occurred regarding the understanding of important factors and processes that determine adequate use of tropical forage plants in pastures. The objective of this text is to provide a brief history of the research on forage plants and grasslands in Brazil, highlighting its evolution, trends, results and transition phases. That will help to put things into perspective and provide the basis for discussing the importance and relevance of studies involving evaluations of morphophysiological traits and responses of forage plants towards planning and definition of sound and efficient grazing management practices. The information is presented in a systematic manner, favouring an integrated view of the different trends and research philosophies used, indicating, critically, the need for revising and changing paradigms as a means of improving and consolidating the knowledge on animal production from pastures.

Key Words: ecophysiology of forage plants, grazing management, morphogenesis

\section{Introdução}

O manejo de pastagens e do pastejo, juntamente com a introdução e avaliação de novos cultivares de gramíneas e leguminosas, têm sido alvos prioritários da experimentação com plantas forrageiras tropicais no Brasil há muito tempo. Tradicionalmente, a grande maioria dos trabalhos de pesquisa, principalmente no que se refere ao manejo do pastejo, possuía um enfoque extremamente simplista e pragmático do processo produtivo. Os resultados colhidos apresentavam, invariavelmente, um caráter muito regional, dificultando a extrapolação para diferentes ecossistemas uma vez que na maioria das vezes não se fornecia informações que permitissem o entendimento e a compreensão das relações de causa e efeito determinantes das respostas de plantas e animais em pastagens, premissa básica para a elaboração e planejamento de práticas de manejo sustentáveis (Da Silva \& Carvalho, 2005; Da Silva \& Nascimento Jr., 2006).

Correspondências devem ser enviadas para: scdsilva@esalq.usp.bredomicio@ufv.br 
Até recentemente, apesar da ênfase dada ao conhecimento da curva de acúmulo de forragem dos pastos após corte ou pastejo, sua estacionalidade de produção, composição morfológica e valor nutritivo da forragem produzida, poucos trabalhos relatavam dados colhidos por períodos que ultrapassassem uma estação de crescimento. $\mathrm{Na}$ grande maioria desses trabalhos, o animal não era parte integrante da proposta experimental, seja porque os experimentos eram baseados em estratégias de corte ou porque os animais eram utilizados apenas como agentes desfolhadores dos pastos. Nesse contexto, o acúmulo de forragem sempre foi considerado como um processo único, singular, sem levar em consideração aspectos dinâmicos relacionados à população de plantas e à competição por luz (Da Silva \& Nascimento Jr., 2006). Adicionalmente, a referência temporal das avaliações, normalmente baseada em uma escala cronológica desvinculada de qualquer característica fisiológica e/ou de desenvolvimento, resultou em um grande número de recomendações e práticas de manejo extremamente generalistas, caracterizadas por uma grande falta de consistência quando de sua colocação em prática sob diferentes condições de ambiente para uma mesma planta forrageira (Da Silva \& Corsi, 2003; Nascimento Jr. et al., 2003; Da Silva, 2004). Carvalho (1997), em uma análise crítica da pesquisa brasileira com animais em pastejo, constatou existir uma preocupação muito grande com o binômio taxa de lotação (ou variável associada)/método de pastejo. Segundo o autor, um dos objetivos principais das pesquisas era a busca pelo método de pastejo ideal para se produzir produto animal comercializável, como se a solução pudesse ser obtida de uma maneira direta, sem se levar em conta aspectos da biologia tanto das plantas forrageiras como dos animais em pastejo. O resultado desse enfoque foi um atraso muito grande no entendimento das relações entre plantas, animais e meio ambiente e, conseqüentemente, um progresso lento no que se refere ao conhecimento acerca do manejo de pastagens. Esse fato foi reconhecido por Moraes et al. (1995) e Nabinger $(1996,1997)$ ao recomendarem a inclusão da ecofisiologia nos estudos com plantas forrageiras, e por Maraschin (2000) ao atribuir esse atraso à não consideração e aplicação dos conhecimentos sobre fisiologia e ecofisiologia de plantas forrageiras nos trabalhos de pesquisa.
Com base nesse cenário, o presente texto tem por objetivo traçar um breve histórico da pesquisa com plantas forrageiras tropicais no país, ressaltar os progressos obtidos, identificar pontos limitantes e apontar novas tendências e metas, colocando em perspectiva a importância do uso e do conhecimento relativo à ecofisiologia de plantas forrageiras para o aprimoramento das práticas de manejo.

\section{Um breve histórico}

As pesquisas com pastagens nos países ditos de pecuária desenvolvida no mundo datam desde o início do século XX. Dentre as publicações científicas da área de agronomia, podem ser destacadas algumas que talvez tenham sido as principais referências para o desenvolvimento de toda a tecnologia desenvolvida pelos pesquisadores responsáveis pela área de manejo de pastagens e que ainda são utilizadas até os dias de hoje. A primeira delas foi o trabalho de Graber em $1927^{3}$, citado por Volenec et al. (1996), que foi um dos primeiros a relatar que a concentração de carboidratos não-estruturais (CNE) nas raízes diminuía imediatamente após desfolhação, durante a fase inicial de rebrotação, em plantas de alfafa (Medicago sativa L.). A segunda foi o trabalho de Watson ${ }^{4}$, citado por Black (1962), que demonstrou que uma medida do tamanho do aparato fotossintético das plantas seria relevante para a comparação de produtividades agrícolas, desenvolvendo o conceito de índice de área foliar (IAF). Um terceiro marco importante foi a publicação dos resultados dos experimentos de Brougham (1955, 1956, 1957, 1958, 1959, 1960), demonstrando a importância do IAF para a compreensão das relações entre interceptação luminosa (IL) pelo dossel e acúmulo de forragem, além da interação entre freqüência e intensidade de desfolhação nos estudos sobre produção e manejo de plantas forrageiras em pastagens.

O trabalho de Brougham (1955) descreveu a natureza sigmóide da curva de rebrotação de pastos

${ }^{3}$ GRABER, L.F. et al. Organic food reserves in relation to the growth of alfafa and other perennial herbaceous plants. Agr. Exp. Sta. Univ. of Wisconsin, Madison, Res. Bul. 80. 1917.

${ }^{4}$ WATSON, D.J. Comparative physiological studies on the growth of field crops!. Variation in net assimilation rate and leaf area between species and varieties, and within and between years. Ann. Bot., Lond. (N.S.) 11:41-76. 1947. 
consorciados de azevém perene, trevo branco e trevo vermelho após desfolhação (variação em massa de forragem com o tempo de rebrotação), bem como a relação assintótica entre IL e IAF (Warren Wilson et al., 1961). Ficou demonstrado que o crescimento das plantas forrageiras estava relacionado com o nível de interceptação de luz pelo dossel e com a sua área foliar (IAF), havendo uma taxa constante de acúmulo de matéria seca (MS) quando havia folhagem suficiente para interceptar praticamente toda a luz incidente. De uma maneira geral, a curva de rebrotação é caracterizada por apresentar três fases distintas. $\mathrm{Na}$ primeira, as taxas médias de acúmulo de MS aumentam exponencialmente com o tempo. Essa fase é altamente influenciada pelas reservas orgânicas da planta, disponibilidade de fatores de crescimento e área residual de folhas após o corte ou pastejo (Brougham, 1957). A segunda fase apresenta taxas médias de acúmulo constantes (fase linear). Nessa fase, o processo de competição inter e intra-específica adquire caráter mais relevante, principalmente quando o dossel se aproxima da completa interceptação da luz incidente. $\mathrm{Na}$ terceira fase inicia-se a queda das taxas médias de acúmulo, ocasionando uma redução na taxa de crescimento, consequiência do aumento da senescência de folhas que atingiram o limite de duração de vida, e aumento do sombreamento das folhas inferiores (mais velhas) (Hodgson et al., 1981).

Esses estudos estimularam o desenvolvimento de modelos de manejo do pastejo baseados nos conceitos de índice de área foliar (IAF) e de acúmulo de carboidratos não-estruturais (CNE), apesar das dificuldades óbvias de se medir tais parâmetros. Esses modelos tinham como objetivo criar condições favoráveis para o crescimento e produção do pasto sob lotação contínua e/ou rotacionada. Assim, na década de 60, Smith (1962), trabalhando com alfafa no norte do EUA, procurou demonstrar em seus experimentos a importância das reservas orgânicas juntamente com o índice de área foliar para o manejo das pastagens sob lotação rotacionada. Durante algum tempo prevaleceu a idéia de que qualquer estratégia de manejo do pastejo deveria sempre levar em consideração o IAF remanescente bem como a concentração de reservas orgânicas nas plantas forrageiras. Alcock (1964) enumerou três conceitos simplificados que, em sua opinião, poderiam explicar as respostas de um pasto quando submetido à desfolhação: (1) disponibilidade total e a reutilização de reservas orgânicas, (2) crescimento radicular, e (3) desenvolvimento da área foliar e interceptação da luz incidente. Desses, o primeiro foi durante muito tempo bastante enfatizado (Weinmann, 1961). No entanto, até onde se sabe, prática de manejo alguma considerou esse fato seriamente. Quanto ao crescimento radicular, apesar de sua importância reconhecida, o conceito não foi utilizado como determinante de práticas de manejo. Em contrapartida, os conceitos de área foliar e interceptação luminosa foram bastante explorados e resultaram em uma série de estudos cujos resultados permitiram compreender melhor o processo de produção de forragem. Apesar disso, Brown \& Blaser (1968) consideraram o uso do IAF para definir estratégias de pastejo como uma simplificação do problema, argumentando que em pastos mantidos altos normalmente existem poucas folhas próximas do nível do solo e que seria necessário um pastejo excessivamente alto para que fosse mantida uma área foliar remanescente suficiente para assegurar máxima interceptação da luz incidente. Os autores argumentaram também que em pastos mantidos altos as folhas localizadas na porção mais baixa do dossel seriam menos eficientes fotossinteticamente, a eficiência de colheita da forragem produzida seria baixa e poderia haver sérios riscos de redução da densidade populacional de perfilhos.

No Brasil, Gomide (1973), no primeiro simpósio sobre o manejo da pastagem realizado na ESALQ em Piracicaba, ao abordar o tema fisiologia do crescimento livre de plantas forrageiras, enfatizou a importância do conceito de IAF, do perfilhamento, dos carboidratos de reserva e da intensidade e freqüência de desfolhação. Jacques (1973) apresentou algumas idéias sobre a fisiologia do crescimento de plantas forrageiras, e apontou duas características consideradas importantes para o manejo: área foliar e reservas orgânicas. Esse autor alertou, no entanto, que o $I A F$, apesar de sua reconhecida importância, não era suficiente para determinar práticas adequadas de manejo. Chamou a atenção para os distintos interesses das diferentes escolas de pesquisa predominantes na época. De um lado, a escola norte-americana, sob a influência do trabalho de 
Graber, especificamente no norte dos Estados Unidos, onde a alfafa tinha maior importância e era utilizada quase que exclusivamente para a produção de feno, razão de seu grande interesse no papel das reservas orgânicas para a rebrotação primaveril (Graber ${ }^{5}$ 1927, citado por Jacques, 1973). Do outro, as escolas inglesa e neozelandesa, sob influência dos trabalhos de Jewiss e Brougham, respectivamente, preconizando a linha de que o vigor da rebrota após a desfolhação dependia de ambos o tamanho e o número de perfilhos vegetativos (Jewiss, 1972), e do IAF e da interceptação de luz pelo dossel (Brougham, 1959) em pastos de azevém perene, espécie forrageira mais utilizada para pastejo em países como Inglaterra e Nova Zelândia.

Muitas das recomendações de manejo do pastejo existentes foram feitas com base no argumento de que, para melhor aproveitar as características de crescimento das plantas forrageiras, o especialista em manejo de pastagens deveria manejar as plantas, em pastejo rotacionado, objetivando obter uma série de rebrotações sucessivas que apresentassem o padrão de crescimento sigmóide. Nesse caso, os pastejos deveriam ser realizados sempre ao final da fase linear de crescimento como forma de obter a máxima taxa média de acúmulo forragem. No entanto, como nessa condição o valor nutritivo da forragem produzida era geralmente baixo, Rodrigues \& Rodrigues (1987) chamaram a atenção para o fato de que poderia ser interessante utilizar as pastagens em estádios menos avançados de crescimento como forma de colher forragem de melhor qualidade. Mais especificamente, a proposta era baseada em realizar desfolhações freqüentes, porém pouco intensas, de modo a evitar períodos de baixa interceptação de luz após cada evento de desfolhação. A intensidade da desfolha deveria assegurar a manutenção de área foliar suficiente para garantir uma rebrotação rápida e assegurar a interceptação completa da luz incidente. Nesse caso, nova interrupção do crescimento do pasto se daria em condições de taxas de acúmulo ligeiramente abaixo do máximo valor possível, uma vez que ao longo da rebrotação a senescência

${ }^{5}$ GRABER, L.F. et al. Organic food reserves in relation to the growth of alfafa and other perennial herbaceous plants. Agr. Exp. Sta. Univ. of Wisconsin, Madison, Res. Bul. 80. 1917.

() 2007 Sociedade Brasileira de Zootecnia ocorre de maneira defasada no tempo do crescimento (folhas em formação são maiores que folhas em senescência) (Parsons et al., 1988). Já para lotação contínua (pastejo contínuo), situação em que os pastos eram mantidos numa condição estável caracterizada por altura e/ou massa de forragem constante, essa proposição de IAF para interceptação de $95 \%$ da luz incidente não se aplicava, uma vez que o processo de senescência era proporcional ao processo de crescimento (folhas em crescimento do mesmo tamanho que folhas em senescência), fazendo com que o acúmulo líquido de forragem fosse nulo ou até eventualmente negativo (Parsons \& Penning, 1988). Nesse caso, a recomendação seria a manutenção dos pastos mais baixos, com um menor IAF, como forma de assegurar uma maior taxa de acúmulo (saldo entre crescimento e senescência) e uma maior colheita de forragem por unidade de área (Parsons et al., 1983b).

A partir de 1960, a escola norte-americana foi influenciada pelos trabalhos de Mott (1960), com a introdução do método de pastejo por ele denominado put and take ou método da taxa da lotação variável. Este era caracterizado pela utilização de um grupo fixo de animais, os chamados animais-teste (ou traçadores), e de um grupo variável de animais, chamados reguladores, adicionados ou retirados do pasto como forma de ajustar a pressão de pastejo. Pressão de pastejo foi definida por esse autor como a quantidade de peso animal (número de animais) por unidade massa de forragem em um determinado ponto no tempo. Como consequiência dessa definição, Mott (1960) cunhou uma outra, ou seja, a capacidade de suporte, que corresponderia à taxa de lotação dos pastos no ponto ótimo de pressão de pastejo. Esse método foi sempre mais utilizado na esfera acadêmica e muito pouco ou quase nada pelo setor produtivo, conseqüência da dificuldade de sua aplicação em condições normais de campo. Durante muito tempo vários pesquisadores utilizaram esses conceitos em seus trabalhos, mas, segundo Maraschin (2000), sem o real conhecimento do significado de suas premissas básicas. Segundo esse mesmo autor, para uma utilização eficiente da forragem produzida deveria ser empregada sempre uma taxa de lotação compatível com a capacidade de suporte da pastagem, isto é, a adoção de uma pressão de pastejo ótima. Percebe- 
se que a escola norte-americana tinha como meta básica buscar o equilíbrio entre o desempenho individual e a produção animal por unidade de área, procurando, assim, obter os melhores resultados econômicos da utilização do pasto sem se preocupar com aspectos básicos da ecofisiologia das plantas forrageiras e com a harmonia do ecossistema pastagem, ou seja, o foco era o de como fazer e não o de por que fazer.

Durante muito tempo a pesquisa com plantas forrageiras no Brasil sofreu forte influência da escola norte-americana. Assim, a ênfase nos trabalhos nacionais de pesquisa com plantas forrageiras passou a ser dada ao conhecimento da curva de acúmulo de forragem dos pastos após corte ou pastejo e de sua estacionalidade de produção e composição morfológica, sendo o acúmulo de forragem considerado como um processo único, singular, sem levar em consideração aspectos dinâmicos relacionados à população de plantas e à competição por luz. Esse fato pode ser constatado a partir das inúmeras palestras apresentadas ao longo dos 30 anos de realização do simpósio sobre o manejo da pastagem da ESALQ (e.g., Maraschin, 1976, 1988, 1997; Corsi, 1976, 1980, 1988, 1997; Barreto, 1976; Blaser, 1988; Leite \& Euclides, 1994; Leite, 1988; Simão Neto, 1986; Hillesheim, 1988; Rodrigues \& Reis, 1995, 1997; Gomide, 1988; Euclides, 1995; Zimmer et al., 1988).

No entanto, Hodgson (1976) já alertava que qualquer variação em um desses parâmetros (e.g. pressão de pastejo, taxa de lotação) poderia influenciar a quantidade de forragem produzida, a proporção da quantidade ofertada realmente consumida e o desempenho produtivo dos animais. Greenhalgh et al. $(1967)^{6}$, citados por Hodgson (1976), sugeriram o uso do inverso da pressão de pastejo ( $\mathrm{kg}$ de forragem $/ \mathrm{kg}$ de peso animal) e introduziu o componente tempo, ou seja, aquilo que veio a ser a ferta de forragem, definida como sendo o peso da forragem disponível por animal por dia. Hodgson (1976) ratificou, portanto, o conceito de oferta de forragem e demonstrou que o consumo era maximizado quando a oferta correspondia de 3 a 4 vezes a capacidade de ingestão do ruminante. Nessa condição, apenas 25

\footnotetext{
${ }^{6}$ GREENHALGH, J.F.D., REID, G.W. and AITKEN, J.N.J.
} agric. Sci. Camb. 69:217-224.1967 a 33\% da forragem ofertada seriam consumidos como forma de assegurar a máxima ingestão de forragem, sendo os 67 a $75 \%$ restantes perdidos na forma de senescência e material morto acumulado na base dos pastos, ou seja, uma baixa eficiência de utilização. Em pastos tropicais esse fato poderia, após sucessivos pastejos, resultar em ofertas de forragem excessivamente altas, caracterizadas por grandes quantidades de material morto e colmos, reduzindo o valor nutritivo da forragem disponível e prejudicando seu consumo pelos animais em pastejo (Stobbs, 1973a,b; Chacon \& Stobbs, 1976).

Mott (1983), ciente dessa dificuldade, chamou a atenção para o fato de que a taxa de conversão da produção primária em produto animal em pastagens tropicais seria bastante diferente daquela em pastagens de clima temperado. Sugeriu então que deveriam ser adotadas práticas de manejo do pastejo em que fosse fornecida ao animal quantidade máxima de tecidos vivos, especialmente folhas, de elevada digestibilidade, com o objetivo de aumentar o consumo e, consequentemente, o desempenho. Surgiu assim o conceito de oferta de matéria seca verde e, posteriormente, o de oferta de folhas que vieram a predominar na experimentação com animais em pastejo no Brasil ao longo dos anos. Nesse novo cenário, ao expressar a oferta diária de forragem na forma de matéria seca verde ou de folhas, desconsiderava-se os componentes morfológicos material morto e colmo, normalmente acumulados em situação de ofertas generosas de forragem, de forma a permitir que a relação clássica de maior oferta maior consumo e desempenho animal, seguindo uma curva assintótica de resposta, fosse obtida de forma consistente (Maraschin \& Jacques, 1993; Xavier et al., 2000; Barbosa et al., 2006; Gontijo Neto et al., 2006 etc.). Contudo, ao se usar esse conceito de oferta de matéria seca verde ou de folhas, ocorria, em médio prazo, um aumento na quantidade de material morto e de colmos na massa de forragem, fato esse que resultou no agravamento da situação que já vinha sendo observada (Stobbs, 1973 a,b; Chacon \& Stobbs, 1976), ou seja, sérias dificuldades de controle dos pastos e produção de forragem passada, de baixo valor nutritivo ( $\mathrm{Da}$ Silva \& Corsi, 2003).

No entanto, ao se analisar a literatura estrangeira disponível, fica claro que já na década

() 2007 Sociedade Brasileira de Zootecnia 
de 70 havia o reconhecimento do conflito existente entre a condição do pasto necessária para obtenção de elevadas taxas de crescimento e acúmulo de forragem e aquela necessária para o máximo consumo e desempenho animal. Parte dessa confusão decorreu das limitações trazidas pela maneira com que se analisava o impacto das práticas de desfolhação sobre a produção de forragem. Esta se baseava apenas na avaliação do acúmulo de forragem sem se levar em conta os vários fluxos de tecidos associados relativos à população de perfilhos no pasto e à renovação de folhas nos perfilhos existentes (Hodgson et al., 1981). No início da década de 80, Bircham \& Hodgson (1983) descreveram, pela primeira vez, o processo dinâmico de acúmulo de forragem em pastos de azevém perene submetidos a intensidades de pastejo por meio de lotação contínua, caracterizando os processos de crescimento e senescência, processos esses antagônicos e concomitantes cujo balanço determinava o acúmulo líquido ou produção de forragem. Ficou demonstrado que os processos de crescimento e senescência eram afetados de maneira diferente pelas práticas de manejo do pastejo e que, por essa razão, avaliações apenas do acúmulo de forragem, sem levar em consideração os processos independentes de crescimento e senescência, poderiam resultar em padrões inconsistentes de resposta das plantas forrageiras à desfolhação. Demonstrou-se também que os padrões de acúmulo de forragem poderiam ser determinados por alterações e manipulação das características estruturais do dossel como IAF, altura e massa de forragem, revelando a possibilidade de trabalhar com metas de pasto como guias de campo para o monitoramento e controle do processo de pastejo.

Segundo Hodgson (1985), um entendimento adequado dos efeitos de variações nas condições do pasto sobre o desempenho tanto de plantas como de animais, e da sensibilidade destes à interferência do manejo, somente poderia ser atingido em estudos baseados no controle e manipulação de características específicas do pasto num estado de equilíbrio (steady state - lotação contínua) ou seguindo um padrão pré-especificado de variação (condições de pré e pós-pastejo). Nesse contexto, Korte et al. (1982), em experimento com pastos de azevém perene submetidos a regimes de corte caracterizados por duas intensidades e duas freqüências de desfolhação, tomaram por base os resultados de Brougham da década de 50 e utilizaram como critério para interromper a rebrotação dos pastos a condição em que os mesmos atingiam $95 \%$ de interceptação da luz incidente ou duas semanas após ter sido atingido esse valor. Concluíram que, durante a fase de desenvolvimento vegetativo das plantas, o critério de $95 \%$ de IL poderia ser utilizado de forma satisfatória, permitindo que a interrupção da rebrotação pudesse ser feita de forma consistente durante o ano e respeitando o ritmo de crescimento das plantas forrageiras. Isso resultaria em maior produção de forragem com elevada proporção de folhas e baixa proporção de material morto. A validade e o potencial de uso do critério de interceptação luminosa como estratégia de manejo da desfolhação foram ratificados por Parsons et al. (1988). Segundo esses autores, seria na condição de IAF crítico, situação em que $95 \%$ da luz incidente são interceptados pelo dossel, que a taxa média de acúmulo de forragem atingiria seu máximo, ou seja, o balanço entre os processos de crescimento e senescência seria máximo, permitindo maior acúmulo de forragem. Esse corresponderia, portanto, ao ponto ideal de interrupção da rebrotação (definidor do intervalo entre cortes e/ou pastejos) e que teria relação direta com o final da fase linear de crescimento da curva sigmóide descrita por Brougham (1955). Esse fato, além de permitir a convergência de conhecimento e informações, ratificou o papel central do IAF na modulação e determinação das respostas de plantas forrageiras ao pastejo, indicando a necessidade de se estudar e compreender melhor aspectos relativos à estrutura do dossel, uso da radiação incidente e balanço dos processos de crescimento e senescência como forma de planejar e definir estratégias de uso e manejo de plantas forrageiras em pastagens.

Em 1993, durante o XVII International Grassland Congress, realizado na Nova Zelândia e Austrália, Chapman \& Lemaire $^{7}$ ratificaram a importância do IAF como determinante das respostas de plantas em pastagens e demonstraram ser essa característica estrutural resultado da

7 CHAPMAN, D.F., LEMAIRE, G. Morphogenetic and structural determinants of plant regrowth after defoliation. In: BAKER, M.J. (Ed.). Grasslands for Our World. SIR Publishing, Wellington, p.55-64, 1993. 
manifestação combinada de características morfogênicas e estruturais das plantas num determinado ambiente. Esse trabalho representou um marco significativo na pesquisa com plantas forrageiras porque integrou os estudos de morfogênese e ecofisiologia à experimentação com pastagens como forma de explicar o funcionamento das plantas, fornecendo a base e o ponto de convergência necessário para a ligação entre as respostas de plantas e animais (interface planta-animal). No Brasil, esse trabalho estimulou uma mudança no enfoque da pesquisa, tradicionalmente pragmática e extremamente aplicada, no sentido de se entender o funcionamento das plantas forrageiras como premissa para planejar sua utilização e manejo. Foi assim que os estudos sobre morfogênese e ecofisiologia de plantas forrageiras tropicais ganharam impulso e o perfil da pesquisa com pastagens no país começou a mudar. Os primeiros trabalhos que abordaram a ecofisiologia das plantas forrageiras tropicais foram os de Pinto et al. (1994 a,b), nos quais foram avaliados os capins andropogon, guiné e setária sob duas doses de $\mathrm{N}$ e foram relatados os resultados acerca das produções de tecido foliar e de colmo, peso médio de perfilhos, proporção de perfilhos vegetativos e reprodutivos, taxas de expansão de área, aparecimento e alongamento foliar. Esses foram, sem dúvida, os primeiros trabalhos publicados na literatura científica brasileira sobre morfogênese. Nota-se que a escolha das espécies trabalhadas na época reflete as opções existentes, o que caracteriza a variabilidade de espécies forrageiras oferecidas pelo mercado nos últimos 20 anos. Apesar de não ter havido continuidade nessa linha de pesquisa por parte dos autores com esses cultivares, provavelmente devido ao rápido aparecimento de novas opções forrageiras, não há dúvida de que esses trabalhos agregaram informações importantes sobre a ecofisiologia dessas espécies tropicais.

Em abril de 1997, Da Silva \& Pedreira ${ }^{8}$ discutiram durante o $3^{\circ}$ Simpósio sobre Ecos-

${ }^{8}$ Da SILVA, S.C.; PEDREIRA, C.G.S. Princípios de ecologia aplicados ao manejo da pastagem. In: $3^{\circ}$ SIMPOSIO SOBRE ECOSSISTEMA DE PASTAGENS, 1997 Jaboticabal, Anais... Jaboticabal, FCAV/UNESP, 1997 p.162 . sistema de Pastagens, realizado em Jaboticabal, SP, o tema Princípios básicos de ecologia aplicados ao manejo da pastagem. Nesse trabalho, enfatizaram a necessidade de se conhecer a estrutura básica da planta e a maneira segundo a qual seus órgãos funcionais e metabolismo respondem aos estresses relacionados com o meio ambiente e com o manejo. Nesse mesmo ano, em um Simpósio Internacional sobre Produção Animal em Pastejo organizado pela Universidade Federal de Viçosa, MG, Gomide (1997) apresentou vários resultados de pesquisas, de sua autoria e de outros pesquisadores brasileiros, sobre morfogênese até aquela data. Afirmou que a estabilização do número de folhas por perfilho e de perfilhos por planta poderia se constituir em um índice para orientar o manejo da desfolhação de plantas forrageiras tropicais. Nesse mesmo simpósio, Lemaire (1997) alertou que a morfogênese das principais espécies tinha que ser analisada de maneira detalhada para que se pudesse entender as formas pelas quais as plantas respondem a variações em condições de meio ambiente e de manejo. Isso consolidou as bases para uma mudança conceitual no planejamento e condu-ção de pesquisas no país.

Dois anos mais tarde, em 1999, foi realizado o primeiro Simpósio sobre Ecofisiologia de Plantas Forrageiras e Ecologia do Pastejo, em Curitiba, PR. O objetivo central foi o de identificar áreas em que o conhecimento era limitado e que precisariam ser trabalhadas, estimulando o debate na comunidade científica nacional no sentido de estipular metas de ação e rumos para a pesquisa com pastagens e promover a conscientização sobre a importância de adotar uma pesquisa de caráter mais sistêmico e integrado, conhecendo as respostas de plantas e animais com base em sua ecologia e ecofisiologia. Nessa oportunidade foram abordados temas como dinâmica e estabilidade de comunidades de plantas, influência da fenologia dos perfilhos e estrutura do dossel forrageiro na interação planta-animal, quantificação e distribuição espacial do pastejo seletivo e seu impacto sobre a população de plantas, cujas contribuições de pesquisadores internacionais renomados em suas áreas de conhecimento foram registradas em um livro, publicado pela $C A B$ International em 2000: Grassland 
Ecophysiology and Grazing Ecology ${ }^{9}$. Hodgson \& Da Silva (2000) chamaram a atenção para a necessidade de se considerar a sustentabilidade em seu sentido restrito, com ênfase na manutenção da produtividade e da estabilidade como metas principais das práticas de manejo idealizadas. Esses autores apontaram ainda que o progresso do conhecimento sobre o comportamento de plantas e animais em pastagens havia sido rápido nos últimos 25 anos, porém um progresso menor havia ocorrido em termos de racionalização dos resultados das interações entre essas populações (interface planta-animal).

Já em 2000 e 2001, durante as Reuniões Anuais da Sociedade Brasileira de Zootecnia realizadas em Viçosa, MG, e Piracicaba, SP, respectivamente, ficou aparente o salto quantitativo e também qualitativo das pesquisas utilizando avaliações relativas à morfogênese e à ecofisiologia das plantas forrageiras tropicais. Esse fato foi ratificado durante o XIX International Grassland Congress, realizado em 2001 na cidade de São Pedro, $\mathrm{SP}^{10}$, e depois na segunda versão do Simpósio Internacional sobre Ecofisiologia de Plantas Forrageiras e Ecologia do Pastejo, realizado em 2004, em Curitiba, $\mathrm{PR}^{11}$. A mensagem agora era muito clara no sentido de que era preciso compreender processos e suas interações e que mais importante que produzir muita forragem era preciso colher muito bem aquilo que era produzido, de forma a assegurar alimento em quantidade e qualidade para os animais em pastejo e a sustentabilidade dos mais diferentes sistemas pastoris brasileiros.

Assim, com a introdução do uso da morfogênese nos protocolos experimentais, palavraschave como crescimento, desenvolvimento, senescência, consumo, utilização e conversão da forragem produzida estão sendo incorporadas lentamente e de maneira irreversível ao vocabulário dos pesquisadores brasileiros. Dificilmente a pesquisa em pastagens conseguirá definir melhor uma proposta de manejo do pastejo sem que sejam observados os processos morfogênicos e o impacto que variações em estrutura do dossel têm sobre a dinâmica do aparecimento e morte de folhas e perfilhos na comunidade de plantas (Nascimento Jr. et al., 2002; Nascimento Jr. et al., 2003; Da Silva, 2004; Da Silva \& Carvalho, 2005; Da Silva \& Nascimento Jr., 2006). O conhecimento das variáveis estruturais e da morfogênese das plantas forrageiras tornou-se, dessa maneira, uma importante ferramenta para a determinação das condições de pasto (altura, massa de forragem, massa de lâminas foliares, IAF etc.) adequadas para assegurar produção animal eficiente e sustentável em áreas de pastagem. Esse posicionamento correspondeu a um marco nos estudos e experimentação com plantas forrageiras tropicais que, ao final da década de 1990 e início dos anos 2000, passaram a assumir uma postura menos pragmática e mais integrada do processo de produção. Nesse contexto, o produto animal passou a ser considerado como sendo o resultado da interação entre solo, clima, planta e animal e o manejo como a forma de criar ambientes pastoris adequados (Carvalho, 2005). Isso foi sumarizado por T.M.S.Freitas $(2003)^{12}$, apud Nabinger et al. (2005), por meio de uma modificação no tradicional modelo proposto por Chapman \& Lemaire (1993) para plantas de clima temperado e adaptado por Sbrissia \& Da Silva (2001) para plantas de clima tropical. Esse modelo é baseado na hipótese de que os recursos tróficos disponibilizados pelo meio $\left(\mathrm{CO}_{2}, \mathrm{~N}\right.$, água, radiação solar e temperatura) ou por práticas de manejo (adubação e/ou fertilização) alteram as características morfogênicas do pasto que, por sua vez, alteram as características estruturais, condicionando assim a taxa de lotação e o comportamento ingestivo dos animais (Figura 1).

Esse novo modelo conceitual de produção animal em pastagens, baseado em uma cadeia de respostas sistêmicas e interligadas em que a

\footnotetext{
9 LEMAIRE, G; HODGSON, J; MORAES, A.; NABINGER, C.e CARVALHO, P.C. de F. Grassland Ecophysiology and Grazing Ecology. Wallingford, CAB International, 422p.

${ }^{10}$ GOMIDE, J.A.; MATTOS, W.R. e Da SILVA, S.C. International Grassland Congress, 19, Piracicaba, 2001. Proceedings... Piracicaba :ESALQ, 2001. 1097p.

${ }^{11}$ PIZARRO, E.; CARVALHO, P.C. de F. e Da SILVA, S.C. International Symposium on Grassland Ecophysiology and Grazing Ecology, 2, Curitiba, 2004. Proceedings... Curitiba : UFPR, 2004. CD-ROM.

${ }^{12}$ FREITAS, T.M.S. Dinâmica da produção de forragem, comportamento ingestivo e produção de ovelhas île de France em pastagem de azevém anual (Lolium multiflorum Lam.) em resposta a doses de nitrogênio. Dissertação de Mestrado. UFRGS. 2003. Orientador: Prof. Paulo César de Faccio Carvalho.
}

๑) 2007 Sociedade Brasileira de Zootecnia 
estrutura do dossel representa o núcleo, o ponto de origem das respostas tanto de plantas como de animais, passou a ser utilizado recentemente como referência para o planejamento e idealização de novas séries de experimentos e pesquisas com plantas forrageiras tropicais. Dessa maneira, o conhecimento relativo à morfogênese e ecofisiologia das plantas forrageiras e à ecologia do pastejo tem adquirido grande importância, assumindo papel de destaque e constituindo premissa básica para a idealização e recomendação de práticas de manejo sustentáveis, que permitam aumentar a produção e a produtividade dos sistemas de produção, respeitando os limites e as características específicas do ecossistema pastagem (Nascimento Jr. et al., 2003).

\section{Morfofisiologia de plantas forrageiras tropicais e o manejo do pastejo}

A mudança filosófica na forma de se encarar o estudo e realizar a pesquisa com plantas forrageiras tropicais no país, feita com base no modelo conceitual apresentado na Figura 1, tem resultado em informações muito interessantes e importantes para a compreensão das respostas de plantas e animais a estratégias de pastejo, tanto em situações de lotação contínua (pastejo contínuo) como de lotação intermitente (e.g., pastejo rotacionado). Estudos recentes realizados com importantes plantas forrageiras tropicais como a Brachiaria brizantha, cultivares Marandu e Xaraés, e o Panicum maximum, cultivares Mombaça e Tanzânia, dentre outras, onde a estrutura do dossel e, ou, seu padrão de variação foram cuidadosamente monitorados, são bons exemplos disso.

De uma maneira geral, os resultados têm revelado que o conceito de IAF crítico, condição na qual o dossel intercepta $95 \%$ da luz incidente, originalmente descrito e aplicado com sucesso para plantas de clima temperado, é válido e pode ser aplicado também para gramíneas tropicais (Barbosa, 2004; Mello \& Pedreira, 2004; Carnevalli et al., 2006; Pedreira, 2006; Zeferino, 2006; Montagner, 2007 13 ), diferentemente do que se postulava (Gomide \& Gomide, 2001). Foram encontradas e descritas relações análogas àquelas existentes na literatura internacional entre a

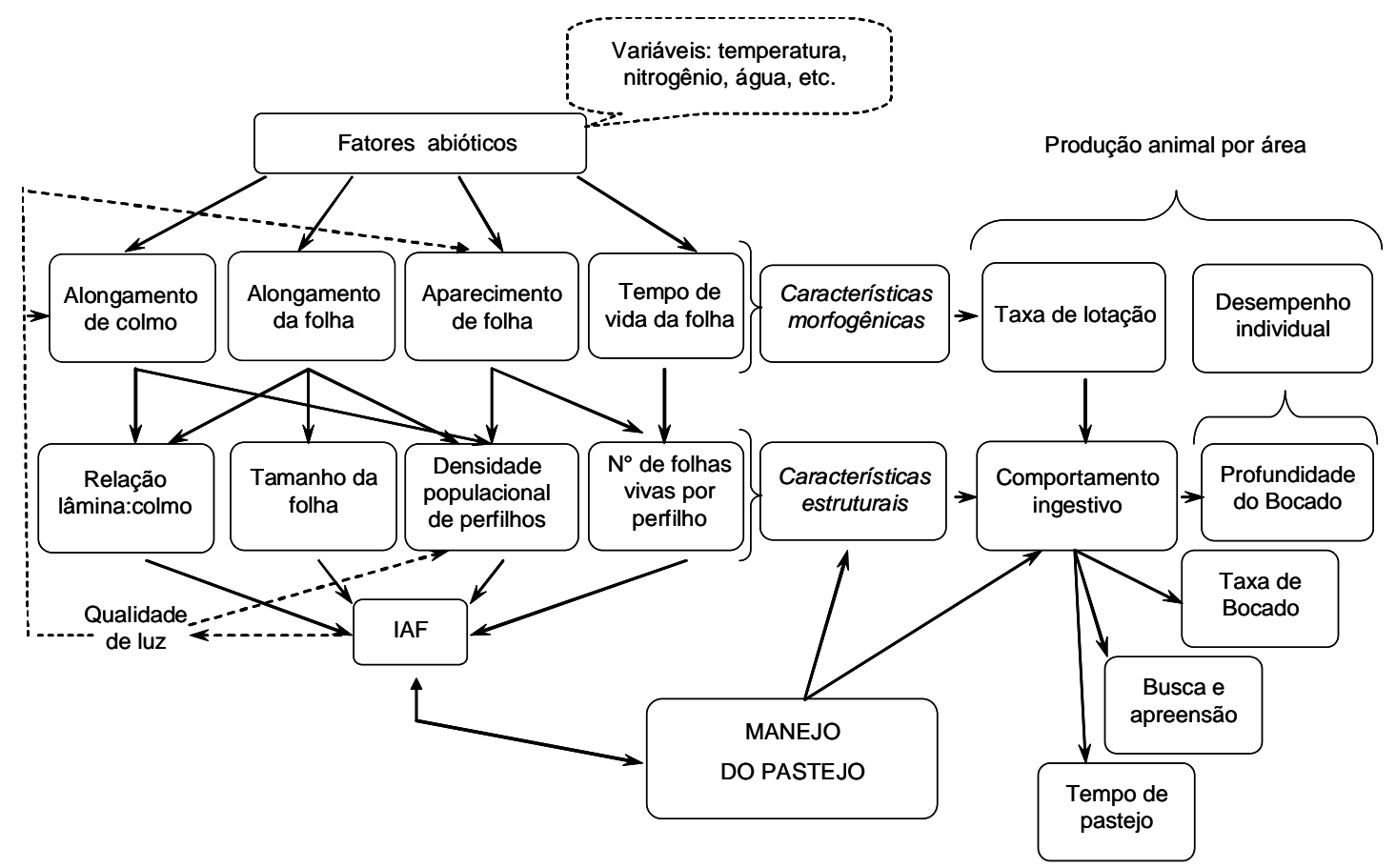

Figura 1 - Modelo conceitual das relações planta-animal no ecossistema pastagem (Adaptado a partir de Chapman \& Lemaire, 1993; Cruz \& Boval, 2000; Sbrissia \& Da Silva, 2001; Freitas, 2003 e Da Silva \& Nascimento Jr., 2006).

${ }^{13}$ MONTAGNER, D.B. Morfogênese e produção de forragem de capim-mombaça sob pastejo. Tese de Doutorado. UFV. Em fase final de preparação. Orientador: Prof. Domicio do Nascimento Junior. 
interceptação de luz pelo dossel e variáveis como acúmulo de forragem, especialmente de folhas, composição morfológica (Barbosa, 2004; Carnevalli et al., 2006; Pedreira, 2006; Zeferino, 2006; Montagner, 2007 ${ }^{12}$ ) e valor nutritivo da forragem produzida (Bueno, 2003; Difante, 2005).

Em uma série de experimentos realizados de forma concomitante na mesma área experimental com Brachiaria brizantha cv. Marandu (capimmarandu) mantido a 10, 20, 30 e $40 \mathrm{~cm}$ de altura sob lotação contínua, Molan (2004) registrou valores de interceptação de luz maiores que $95 \%$ em pastos mantidos acima de $10 \mathrm{~cm}$. O acúmulo total de forragem ao longo dos 360 dias de período experimental foi semelhante para os pastos mantidos na amplitude de alturas estudada, com tendência de redução naqueles mantidos a $40 \mathrm{~cm}$ (Figura 2).

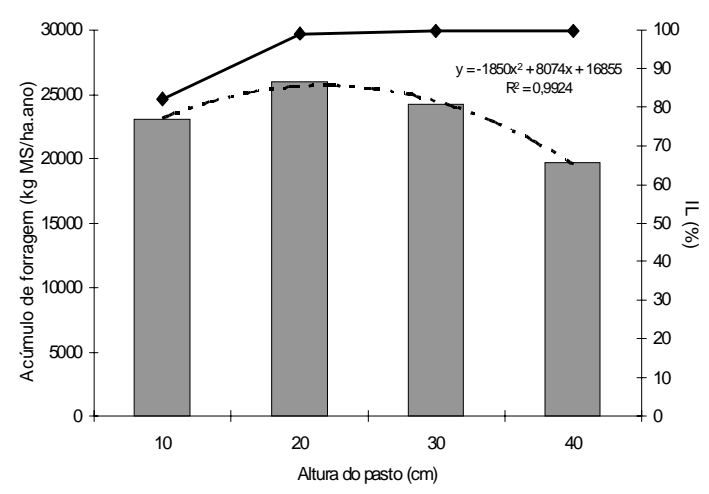

$\square$ Acúmulo de forragem $\longrightarrow$ - hterceptação de luz - - - Polinômio (Acúmub de forragem)

Figura 2 - Interceptação de luz e acúmulo total de forragem em pastos de capim-marandu mantidos a 10, 20, 30 e $40 \mathrm{~cm}$ de altura por meio de lotação contínua e taxa de lotação variável de janeiro a dezembro de 2002 (Molan, 2004).

Avaliação da estrutura do dossel revelou que a densidade de forragem e de IAF dos pastos aumentou do topo em direção ao nível do solo, com maior proporção de folhas e área foliar localizada na porção mediana superior, e de colmos e de material morto na porção mediana inferior do dossel. Em termos relativos, a profundidade de folhas no dossel correspondeu a um valor relativamente constante e em torno de $50 \%$ da altura, o que correspondeu a $5,10,15$ e $20 \mathrm{~cm}$ para nos pastos mantidos a 10, 20, 30 e $40 \mathrm{~cm}$, respectivamente (Figura 3).
Avaliações relativas às características morfogênicas e padrões de desfolhação de perfilhos individuais revelaram que a cada evento de desfolhação cerca de $2 / 3$ ou $67 \%$ do comprimento do limbo foliar das folhas era removido independentemente da altura de pasto sendo avaliada e da freqüência dos eventos de desfolhação ocorridos (Gonçalves, 2002). Esta, por sua vez, apresentou relação direta e linear com a taxa de lotação e, ou, a altura em que os pastos eram manejados, de forma que pastos mantidos mais baixos, por meio do emprego de maiores taxas de lotação, eram desfolhados mais frequentemente que pastos mantidos mais altos (Figura 4).

Os valores de intervalo entre desfolhações sucessivas (inverso da freqüência de desfolhação) associados aos de duração de vida das folhas, e tomando-se como referência a remoção de $2 / 3$ do comprimento do limbo foliar por evento de desfolhação, resultaram em valores de eficiência de utilização (proporção do crescimento que não é perdido por senescência) elevados e decrescentes com a altura de pasto avaliada $(82,3 ; 76,2 ; 69,4 \mathrm{e}$ $68,7 \%$ para os pastos mantidos a $10,20,30$ e 40 $\mathrm{cm}$, respectivamente) (Gonçalves, 2002).

A combinação dos resultados de Molan (2004) e de Gonçalves (2002) revelou que o estrato pastejável do capim-marandu manejado sob lotação contínua correspondia a $33 \%$ da altura, ou seja, os primeiros 3,3;6,6; 9,9 e 13,2 cm do estrato superior para os pastos mantidos a 10, 20, 30 e $40 \mathrm{~cm}$, respectivamente. Esse resultado explicou as grandes variações em massa de bocado (0,5; 0,8; 1,2 e 1,5 g MS/bocado), consumo diário de forragem $(1,3 ; 1,8 ; 1,8$ e 2,0 kg MS/100 kg peso) (Sarmento, 2003) e, consequentemente, desem-penho animal (0,190; 0,510; 0,750 e 0,930 $\mathrm{kg} /$ novilha.dia) mensuradas, uma vez que não houve diferença em valor nutritivo da forragem consu-mida (média de $12,5 \%$ de proteína bruta e $64,7 \%$ de digestibilidade da matéria seca; Andrade, 2003).

Avaliações mais detalhadas sobre a dinâmica do processo de acúmulo de forragem nos pastos de capim-marandu sob lotação contínua (Sbrissia, 2004) revelaram um padrão de resposta análogo àquele descrito por Bircham \& Hodgson (1983) para azevém perene, apontando para uma amplitude de condições de pasto entre 20 e $40 \mathrm{~cm}$ em que a taxa de acúmulo líquido era praticamente

\section{2007 Sociedade Brasileira de Zootecnia}




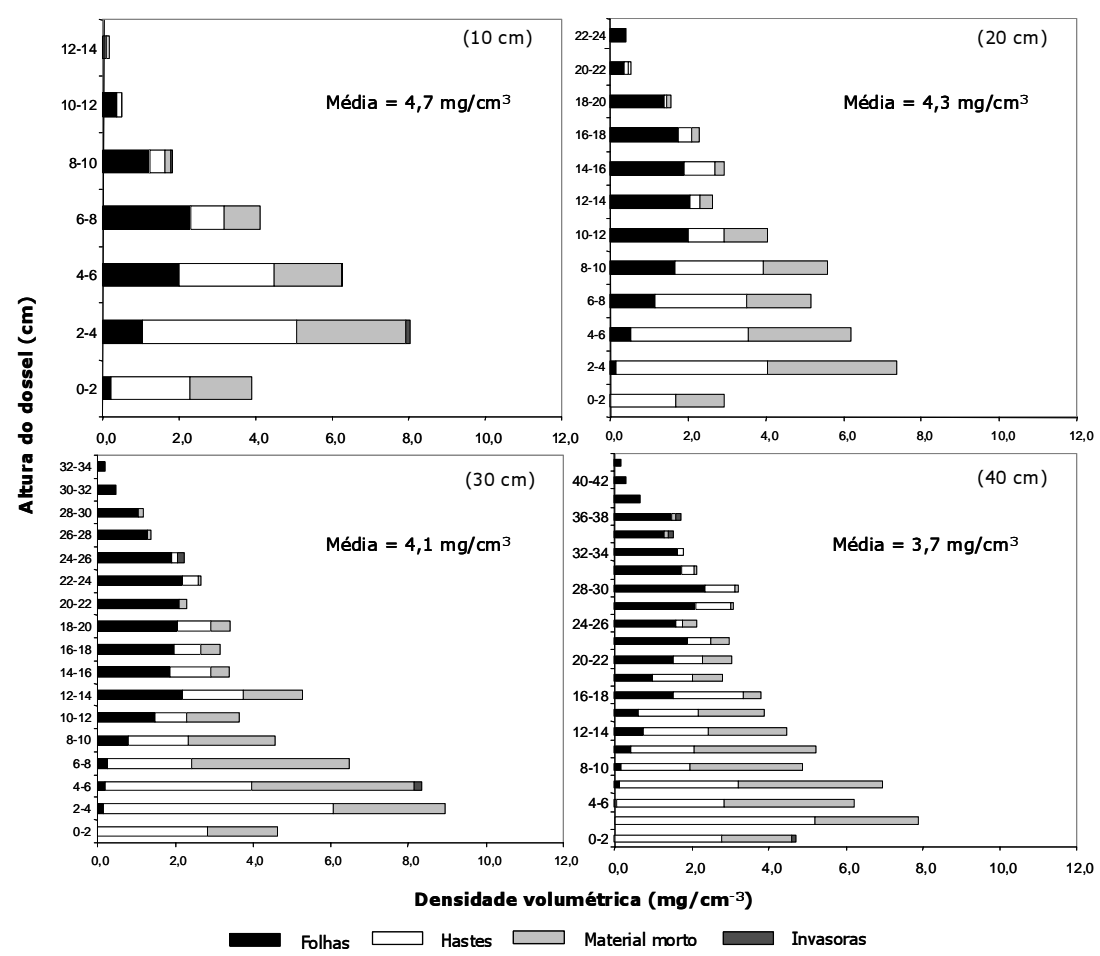

Figura 3 - Estrutura do dossel forrageiro de pastos de capim-marandu (Brachiaria brizantha cv. Marandu) mantidos a 10, 20, 30 e $40 \mathrm{~cm}$ de altura sob lotação contínua por bovinos de corte durante o período de janeiro a março de 2002 (Molan, 2004).

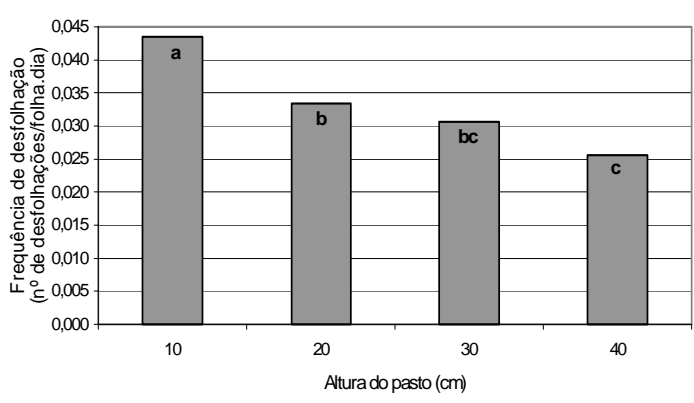

Figura 4 - Freqüência de desfolhação de folhas individuais em pastos de capim-marandu (Brachiaria brizantha cv. Marandu) mantidos a 10,20, 30 e $40 \mathrm{~cm}$ de altura sob lotação contínua por bovinos de corte de novembro de 2001 a fevereiro de 2002 (Gonçalves, 2002).

constante (Figura 5), corroborando os resultados de Molan (2004) (Figura 2), além de sugerir a necessidade de se trabalhar com metas de altura variáveis ao longo do ano como forma de otimizar o acúmulo e a utilização de forragem (pastos mantidos mais baixos durante o outono e inverno e mais altos durante a primavera e verão). Essa relativa estabilidade da produção foi consequiência de uma compensação entre número, área foliar

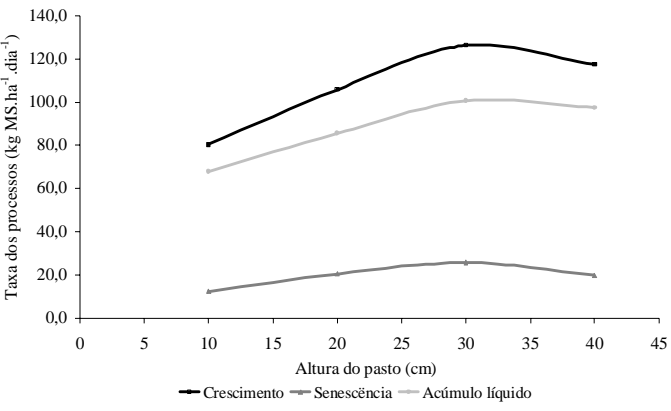

Figura 5 - Dinâmica do acúmulo de forragem em pastos de capim-marandu (Brachiaria brizantha $\mathrm{cv}$. Marandu) mantidos a 10, 20, 30 e $40 \mathrm{~cm}$ de altura sob lotação contínua por bovinos de corte durante o período de janeiro a março de 2002 (Sbrissia, 2004).

e peso de perfilhos individuais, de tal forma que pastos mantidos mais baixos possuíam uma alta densidade populacional de perfilhos pequenos e vice-versa (Figura 6).

Sob condições de lotação intermitente, cuja modalidade mais comum é o pastejo rotacionado, um padrão bastante consistente de respostas foi constatado em uma segunda série de experimentos realizados em localidades distintas, por equipes

() 2007 Sociedade Brasileira de Zootecnia 


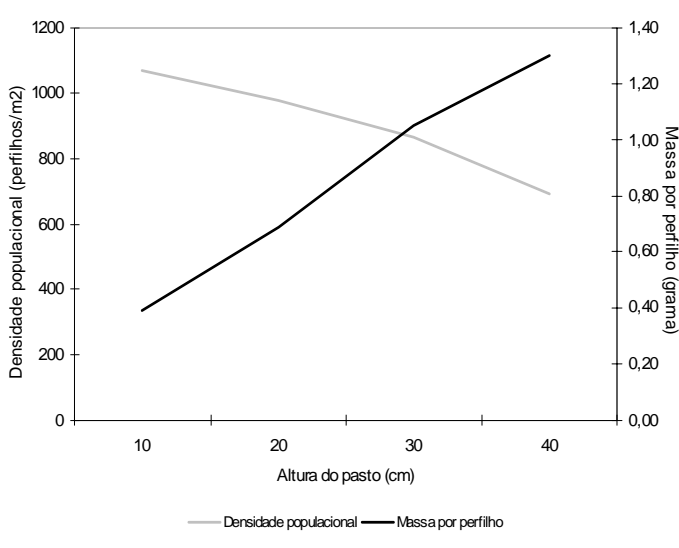

Figura 6 - Densidade populacional e tamanho de perfilhos em pastos de capim-marandu (Brachiaria brizantha cv. Marandu) mantidos a $10,20,30$ e $40 \mathrm{~cm}$ de altura sob lotação contínua por bovinos de corte durante o período de janeiro a dezembro de 2002 (Sbrissia, 2004).

diferentes, porém utilizando protocolos análogos de avaliação. Foram utilizados os capins Panicum maximum cv. Mombaça e Tanzânia e Brachiaria brizantha cv. Marandu e Xaraés, e definidas duas condições de referência para a utilização dos pastos, conforme sugerido por Hodgson (1985):

(a) uma de pré-pastejo, definindo o momento da entrada dos animais nos pastos para realizar o pastejo (interrupção da rebrotação), e

(b) outra de pós-pastejo, definindo o momento de retirada dos animais dos pastos e encerramento do pastejo (início de um novo período de rebrotação).

Como condição pré-pastejo para os capins mombaça e marandu foram utilizados os valores de 95 e $100 \%$ de IL, com variações para os capins tanzânia e xaraés. No caso do capim-tanzânia foi utilizado um terceiro nível de IL $(90 \%)$ e para o capim-xaraés uma terceira condição correspondente a um período de descanso ou de rebrotação fixo de 28 dias. A condição pós-pastejo foi caracterizada por alturas de resíduo de 30 e $50 \mathrm{~cm}$ para o capim-mombaça, 25 e $50 \mathrm{~cm}$ para o capimtanzânia, 10 e $15 \mathrm{~cm}$ para o capim-marandu e um valor único de $15 \mathrm{~cm}$ para o capim-xaraés. Os valores mais baixos foram planejados com o objetivo de se obter alta eficiência de pastejo sem, contudo, representarem desfolhações excessivamente severas de forma a prejudicar as plantas, e os valores mais altos foram julgados representar uma condição menos estressante para as plantas e mais próxima daquela normalmente utilizada em condições de campo.

A estrutura dos pastos na condição pré-pastejo revelou padrão análogo àquele descrito por Molan (2004) para o capim-marandu sob lotação contínua. A densidade de forragem e de IAF foi elevada do topo em direção ao nível do solo, com maior proporção de folhas e área foliar localizada na porção mediana superior, e de colmos e de material morto na porção mediana inferior do dossel, independentemente da planta forrageira avaliada (Bueno, 2003; Difante, 2005; Lopes, 2006; Pedreira, 2006; Trindade, 2007; Souza Júnior, $\left.2007^{14}\right)$. Avaliações da dinâmica do acúmulo de forragem durante o período de rebrotação de sucessivos ciclos de pastejo revelaram que no início o processo é caracterizado pelo acúmulo quase exclusivo de folhas. $\mathrm{O}$ acúmulo de colmos e de material morto é incrementado de maneira significativa somente a partir da condição em que o dossel intercepta $95 \%$ da luz incidente, ou seja, atinge seu IAF crítico. Essa condição de $95 \%$ de IL esteve altamente correlacionada com a altura do dossel durante a rebrotação, e correspondeu a $90 \mathrm{~cm}$ para o capim-mombaça (Carnevalli, 2003; Montagner, $2007^{15}$ ), $70 \mathrm{~cm}$ para o capim-tanzânia (Mello \& Pedreira, 2004; Barbosa, 2004; Zannini, $2007^{16}$ ), $25 \mathrm{~cm}$ para o capim-marandu (Zeferino, 2006) e $30 \mathrm{~cm}$ para o capim-xaraés (Pedreira, 2006), independentemente da época do ano (Figura 7).

Em capim-tanzânia, pastejos realizados com 90\% de IL resultaram em menor acúmulo total de matéria seca, porém acúmulo semelhante de folhas em relação à condição de 95\% IL. Já os pastejos realizados com $100 \%$ IL resultaram em acúmulo semelhante de matéria seca total e menor de folhas, indicando que antes de $95 \%$ IL a produção de

${ }^{14}$ SOUZA JUNIOR, S.J. Estrutura do dossel, interceptação de luz e acúmulo de forragem em pastos de capim-marandu submetidos a estratégias de pastejo rotacionado por bovinos de corte. Dissertação de Mestrado. USP/ESALQ Em fase final de preparação. Orientador: Prof. Sila Carneiro da Silva.

${ }^{15}$ MONTAGNER, D.B. Morfogênese e produção de forragem de capim-mombaça sob pastejo. Tese de Doutorado. UFV. Em fase final de preparação. Orientador: Prof. Domicio do Nascimento Junior.

${ }^{16}$ ZANINE, A.M. Características morfogênicas e estruturais, acúmulo de forragem e valor nutricional do capim-tanzânia submetido a intensidades e freqüências de pastejo. Tese de Doutorado. UFV. Em fase final de preparação. Orientador: Prof. Domicio do Nascimento Junior. 
forragem seria limitada por interceptação subótima da luz incidente e depois de $95 \%$ IL por perdas excessivas por senescência e morte de tecidos (Barbosa, 2004), de forma semelhante àquela descrita por Parsons \& Penning (1988) e Parsons et al. (1988) para azevém perene. Este fato ratifica e dá suporte ao uso do critério de $95 \%$ de IL como referência para a interrupção da rebrotação, uma vez que corresponde à condição em que a maior taxa de acúmulo de folhas é obtida, além de poder ser facilmente identificada no campo por meio da altura do pasto. No caso do capim-xaraés, um outro fator interessante que merece destaque é o padrão de acúmulo de forragem resultante da estratégia de pastejo caracterizada por um período fixo de descanso de 28 dias. Esta foi caracterizada por um padrão de acúmulo que variou entre aquele das estratégias de 95 e $100 \%$ de IL dependendo da época do ano e das condições de crescimento vigentes. Durante o período de setembro a dezembro de 2005 (primavera), caracterizado por temperaturas médias mais baixas, menor precipitação pluvial e menor disponibilidade de radiação luminosa, o período de descanso de 28 dias apresentou um padrão de resposta mais próximo daquele correspondente à estratégia de $95 \%$ de IL. Nessas condições, a velocidade de crescimento das plantas é menor e o dossel necessita de um maior
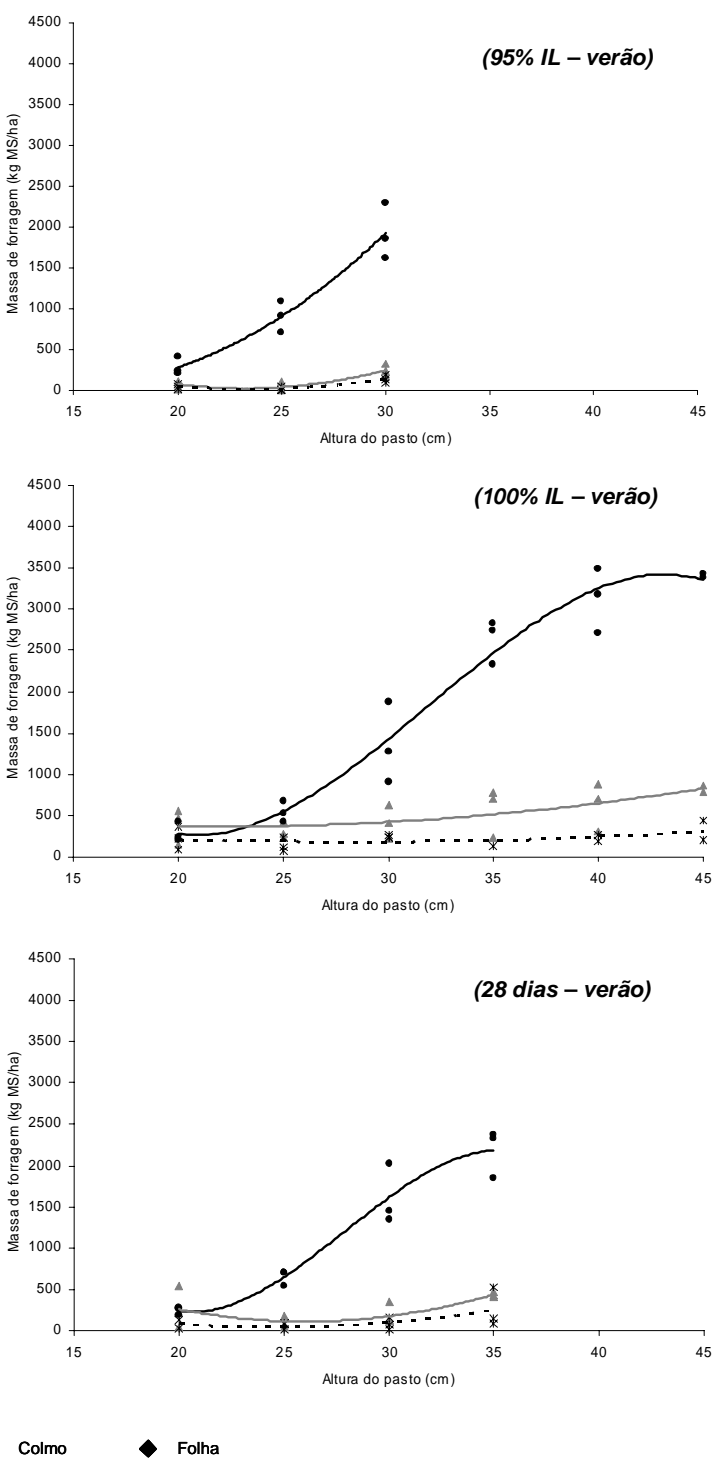

Figura 7 - Padrão de variação na massa de forragem ao longo da rebrotação em pastos de capim-xaraés (Brachiaria brizantha cv. Xaraés) submetidos a estratégias de pastejo rotacionado durante o período de setembro de 2005 a fevereiro de 2006 (Pedreira, 2006). Valores considerados acima da altura de resíduo de $15 \mathrm{~cm}$. 
número de dias para fechar (atingir $95 \%$ de IL e, ou, $30 \mathrm{~cm}$ de altura) e iniciar processo intenso de competição por luz, situação em que o acúmulo de colmos e a senescência são drasticamente intensificados (Figura 7). Por outro lado, durante o período de janeiro a fevereiro de 2006 (verão), com o aumento generalizado da disponibilidade de fatores de crescimento e maior velocidade de rebrotação, o período de descanso de 28 dias representou, em termos fisiológicos para a planta, um descanso mais longo. Nessa época foi necessário um menor número de dias para atingir $95 \%$ de IL e, ou, $30 \mathrm{~cm}$ de altura, resultando em um padrão de acúmulo de forragem mais próximo daquele de pastos submetidos à estratégia de $100 \%$ IL (Pedreira, 2006). Esse padrão distinto de comportamento em função da época do ano e, ou, condições de crescimento resultou em valores de altura de dossel e massa de forragem (acima do resíduo de $15 \mathrm{~cm}$ ) diferentes para os mesmos 28 dias de descanso $(30 \mathrm{~cm}$ e $2140 \mathrm{~kg}$ MS/ha na primavera e $35 \mathrm{~cm}$ e $2870 \mathrm{~kg} \mathrm{MS} / \mathrm{ha}$ no verão, respectivamente) e $100 \%$ de IL (40 cm e $5220 \mathrm{~kg}$ MS/ha na primavera e $45 \mathrm{~cm} \mathrm{e} 4410 \mathrm{~kg} \mathrm{MS} / \mathrm{ha}$ no verão, respectivamente) em contraste com a estratégia de $95 \%$ de IL (30 cm e $2160 \mathrm{~kg} \mathrm{MS} / \mathrm{ha}$ na primavera e $30 \mathrm{~cm}$ e $2300 \mathrm{~kg} \mathrm{MS} /$ ha no verão, respectivamente), que apresentou valores relativamente estáveis para essa variáveis. Esse fato demonstra a inconsistência de respostas e a limitação de se adotar e, especialmente generalizar, um período de descanso fixo e definido a priori, uma vez que dependendo da época do ano e das condições vigentes de crescimento este pode ser demasiadamente curto, o que levaria a perdas de produção em termos de quantidade, ou demasiadamente longo, o que levaria a perdas de quantidade e qualidade, podendo, inclusive, resultar em degeneração da estrutura e, eventualmente, degradação dos pastos.

O prolongamento do período de descanso ou do intervalo entre pastejos além da condição em que o dossel interceptava $95 \%$ da luz incidente resultou em aumento da massa de forragem por ocasião da entrada dos animais nos pastos (100\% IL ou 28 dias durante o verão - Figura 7). Porém, essa maior massa de forragem é gerada, basicamente, pelo acúmulo de colmos e de material morto, uma vez que o acúmulo de folhas se estabiliza e, ou, diminui a partir de $95 \%$ de IL
(Barbosa, 2004; Carnevalli et al., 2006; Pedreira, 2006; Zeferino, 2006). Nessa condição, o maior acúmulo de forragem por ciclo de pastejo pode ser parcial ou totalmente compensado pelo menor número de pastejos na estação de crescimento (períodos de descanso mais longos) (Carnevalli, 2003; Barbosa, 2004; Pedreira, 2006), além de o valor nutritivo da forragem em oferta ser reduzido (Bueno, 2003) e haver aumento na presença de colmos e material morto nos estratos superiores do dossel, o que pode prejudicar o processo de preensão e consumo de forragem (Trindade, 2007).

Em uma série de trabalhos baseados no uso de metas de altura do pasto e não de interceptação de luz pelo dossel, Silva (2004) avaliou o efeito da altura em pastos de capim-mombaça por ocasião do início do período de pastejo $(60,80,100,120$ e $140 \mathrm{~cm}$ ). Os resultados revelaram que a taxa de consumo de forragem de novilhas leiteiras aumentou com o aumento da altura pré-pastejo e atingiu um valor máximo por volta de $90-100 \mathrm{~cm}$, ponto a partir do qual passou a diminuir até a altura de $140 \mathrm{~cm}$. Esse comportamento foi explicado por um aumento linear na massa de bocado com alturas crescentes de pastejo compensado por uma freqüência de bocados muito baixa nas maiores alturas de pasto. A altura de $90 \mathrm{~cm}$ é aquela em que $95 \%$ da luz incidente são interceptados (Carnevalli, 2003; Montagner, $2007^{17}$ ), sugerindo uma conver-gência entre as respostas de plantas e animais em relação à variação em estrutura do dossel forrageiro e apontando a condição de $95 \%$ de IL como ideal. Esse fato foi demonstrado e corroborado pelos resultados do trabalho de Hack (2004), em que se avaliou o efeito de estruturas contrastantes de pasto de capim-mombaça (estruturas baixa e alta - 90 e $140 \mathrm{~cm}$, respectivamente) sobre desempenho de vacas leiteiras. Nessa condição, a produção diária de leite das vacas que iniciaram o pastejo nos pastos com $90 \mathrm{~cm}$ de altura foi 14,0 e aquela das vacas nos pastos com 140 $\mathrm{cm}$ de altura foi $10,8 \mathrm{~kg} / \mathrm{vaca}$, ou seja, uma diferença de cerca de 30\%. Difante (2005), partindo dessa mesma premissa, avaliou pastos de capim-tanzânia submetidos a estratégias de pastejo rotacionado definidas por pastejos com $95 \%$ de

${ }^{17}$ MONTAGNER, D.B. Morfogênese e produção de forragem de capim-mombaça sob pastejo. Tese de Doutorado. UFV. Em fase final de preparação. Orientador: Prof. Domicio do Nascimento Junior. 
IL (ou 70 cm de altura pré-pastejo) e resíduos póspastejo de 25 e $50 \mathrm{~cm}$. Os resultados revelaram um maior ganho de peso por animal $(0,800 \mathrm{vs}$ $0,660 \mathrm{~kg} /$ novilho.dia), menor taxa de lotação $(4,9$ vs 6,1 novilhos de $300 \mathrm{~kg} / \mathrm{ha}$ ) e menor eficiência de pastejo (50 vs 90\%) quando os pastos foram rebaixados a $50 \mathrm{~cm}$ comparativamente àqueles rebaixados a $25 \mathrm{~cm}$ de resíduo pós-pastejo. $\mathrm{O}$ menor desempenho animal nos pastos manejados a $25 \mathrm{~cm}$ de resíduo foi conseqüência de uma redução de $20 \%$ no consumo diário de forragem, uma vez que não houve diferença em termos de valor nutritivo da forragem consumida. Esses resultados demonstram a importância do ajuste da intensidade de pastejo (resíduo pós-pastejo) como forma de regular o nível de desempenho animal almejado, ajustar a eficiência de colheita da forragem produzida e gerar flexibilidade de manejo no sistema de produção. A freqüência de pastejo, definida de forma adequada, assegura produção de forragem em quantidade e bom valor nutritivo, favorecendo o desempenho animal.

Basicamente, o conjunto e padrões de resposta descritos é resultado de alterações na estrutura do dossel forrageiro ao longo da rebrotação, caracterizadas por alterações significativas na proporção e distribuição de folhas, colmos e material morto no perfil vertical do dossel, na relação lâmina: colmo, na densidade volumétrica da forragem e no comprimento final das lâminas foliares, dentre outras (Da Silva \& Carvalho, 2005). De uma maneira geral, o valor nutritivo da forragem consumida quando os pastejos são realizados com 95\% de IL é bastante estável e caracterizado por concentrações de proteína bruta da ordem de 14 a $18 \%$ e digestibilidade da matéria seca de 60 a $70 \%$ (Andrade, 2003; Bueno, 2003; Difante, 2005), compatíveis, portanto, com níveis satisfatórios de desempenho para vacas leiteiras e animais de engorda. Resultados recentes com outros cultivares de Panicum maximum como Tobiatã, Massai e Atlas (Moreno, 2004) e com Pennisetum purpureum cv. Cameroon (Voltolini, 2006) ratificam e corroboram o padrão de resposta descrito acima, apontando para uma nova realidade e uma nova janela de oportunidades em termos de pesquisa e experimentação com plantas forrageiras tropicais.

\section{Perspectivas futuras}

Apesar da significativa variação morfológica das espécies avaliadas, diferentes locais experimentais e métodos de pastejo empregados, os resultados demonstram a importância que a estrutura do dossel forrageiro tem sobre o acúmulo e o valor nutritivo da forragem produzida e, consequentemente, sobre o comportamento ingestivo, consumo e desempenho dos animais em pastejo. Nesse contexto, a idealização e formulação de estratégias de manejo do pastejo com base em metas de pasto, particularmente altura, passam a ser uma alternativa real e premissa básica para a melhoria e aumento da eficiência produtiva e da produção dos sistemas de produção animal em pastagens tropicais. Práticas de manejo definidas dessa forma permitiriam um grande avanço, adicional àquele já alcançado, e propiciaria condições de ajuste fino nas atuais práticas de manejo do pastejo vigentes no país.

Nesse contexto, o estudo e a avaliação de respostas morfofisiológicas e morfogênicas das plantas forrageiras tropicais renovam sua importância e assumem papel central no entendimento e planejamento de estratégias e práticas de manejo do pastejo, uma vez que definirão os limites de flexibilidade e de uso tanto de plantas como de animais na composição de sistemas de produção animal em pastagens. Adicionalmente, significa uma mudança de paradigma muito importante, uma vez que a pesquisa nacional passa a buscar a resposta para a pergunta por que como forma de responder e implementar o como fazer e não o contrário. Esse corresponde a um salto qualitativo muito grande e poderá representar o marco da passagem do Brasil para o cenário de país desenvolvido na pecuária. Para atingir essa condição uma mudança de atitude será fundamental, assumir e reconhecer que a produção animal em pasta-gens é um problema multidisciplinar, requerendo, portanto, trabalho integrado e esforço cooperativo entre grupos de pesquisa e pesquisadores.

\section{Literatura citada}

ALCOCK, M.B. The physiological significance of defoliation on the subsequent regrowth of grass-clover mixtures and cereals. In: D.J. CRISP (Ed.) Grazing in terrestrial and marine environments. Oxford. Blackwell Sci. Pub., 1964.p. 25-41.

() 2007 Sociedade Brasileira de Zootecnia 
ANDRADE, F.M.E. Produção de forragem e valor alimentício do capim-marandu submetido a regimes de lotação contínua por bovinos de corte. Dissertação (Mestrado em Agronomia - Ciência Animal e Pastagens), Escola Superior de Agricultura "Luiz de Queiroz", Universidade de São Paulo, 125p., 2003.

BARBOSA, M.A.F.; NASCIMENTO Jr., D; CECATO, U. Dinâmica da pastagem e desempenho de novilhos em pastagem de capim-tanzânia sob diferentes ofertas de forragem. Revista Brasileira de Zootecnia, v.35, n.4, p.1594-1600, 2006 (supl.).

BARRETO, I.L. Pastejo contínuo. In: PEIXOTO, A.M.; MOURA, J.C.; FURLAN, R.S.; FARIA, V.P. (Eds.) Simpósio sobre manejo da pastagem, 3. Piracicaba, 1976. Anais... Piracicaba:FEALQ, 1976. p.219-251.

BIRCHAM, J.S.; HODGSON, J. The influence of swards conditions on rates of herbage growth and senescence in mixed swards under continuous grazing management. Grass and Forage Science, v.38, n.4, p. 323-331, 1983.

BLASER, R.E. Pasture-animal management to evaluate plants and to develop forage systemas. In: PEIXOTO, A.M., MOURA, J.C., FARIA, V.P. (Eds.) SIMPÓSIO SOBRE MANEJO DA PASTAGEM, 9, Piracicaba, 1988. Anais.. Piracicaba : FEALQ, 1988. p.01-40.

BUENO, A.A.O. Características estruturais do dossel forrageiro, valor nutritivo e produção de forragem em pastos de capim-Mombaça submetidos a regimes de desfolhação intermitente. Dissertação (Mestrado em Agronomia - Ciência Animal e Pastagens) - Escola Superior de Agricultura "Luiz de Queiroz", Piracicaba. 124p. 2003.

CARNEVALLI, R.A. Dinâmica da rebrotação de pastos de capim-Mombaça submetidos a regimes de desfolhação intermitente. Tese (Doutorado em Ciência Animal e Pastagens) - Escola Superior de Agricultura "Luiz de Queiroz", Piracicaba. 136p., 2003.

CARVALHO, P.C. de F. O manejo da pastagem como gerador de ambientes pastoris adequados à produção animal. In: MOURA, J.C.; DA SILVA, S. C; DE FARIA, V.P. (Eds.) SIMPÓSIO SOBRE MANEJO DA PASTAGEM, 22., 2005, Anais... Piracicaba: FEALQ, 2005. p.07-31.

CHACON, E.; STOBBS, T.H. Influence of progressive defoliation of a grass sward on the eating behaviour of cattle. Australian Journal of Agricultural Research, v.27, p.709727, 1976.

CHAPMAN, D.F.; LEMAIRE, G. Morphogenetic and structural determinats of plant regrowth after defoliation. In: BAKER, M.J. (Ed.). Grassands for our world. Sir Publishing, Wellington, p. 55-64, 1993.

CORSI, M. Adubação nitrogenada das pastagens. In: PEIXOTO, A. M.; MOURA, J.C.; FURLAN, R. S.; FARIA, V.P. (Eds.) SIMPÓSIO SOBRE MANEJO DA PASTAGEM, 2, 1975. Piracicaba. Anais... Piracicaba : FEALQ, 1975, p.112135 .

CORSI, M. Espécies forrageiras para pastagem. In: PEIXOTO, A.M.; MOURA, J.C.; FURLAN, R.S.; FARIA V.P. (Eds.) SIMPÓSIO SOBRE O MANEJO DA PASTAGEM, 3, 1976 Piracicaba. Anais... Piracicaba: FEALQ, 1976, p.5-44.

CORSI, M. Parâmetros para instensificar o uso das pastagens. In: PEIXOTO, A.M.; MOURA, J.C.; FARIA, V.P. (Eds.) SIM-PÓSIO SOBRE MANEJO DA PASTAGEM, 6 , Piracicaba, 1980. Anais... Piracicaba: FEALQ, 1980. p.214263.

CORSI, M. Manejo de plantas forrageiras do gênero Panicum. In: PEIXOTO, A.M.; MOURA, J.C.; FARIA, V.P. (Eds.) SIMPÓSIO SOBRE MANEJO DA PASTAGEM, 9, Piracicaba, 1988. Anais... Piracicaba:FEALQ, 1988. p.5776.

CORSI, M.; MARTHA Jr., G.B. Manutenção da fertilidade do solo em sistemas intensivos de pastejo rotacionado. In: PEIXOTO, A.M.; MOURA, J.C.; FARIA, V.P. (Eds.)
SIMPÓSIO SOBRE MANEJO DA PASTAGEM, 14, Piracicaba, 1997. Anais... Piracicaba: FEALQ, 1997, p.161192.

DA SILVA, S.C. Understanding the dynamics of herbage accumulation in tropical grass species: the basis for planning efficient grazing management practices. In: PIZARRO. E.; CARVALHO, P.C.F.; DA SILVA, S.C. (Eds.) SYMPOSIUM ON GRASSLAND ECOPHYSIOLOGY AND GRAZING ECOLOGY, 2., 2004,UFPR, Curitiba. Anais... Curitiba. CDROM.

DA SILVA, S.C.; CORSI, M. Manejo do pastejo. In: PEIXOTO, A.M.; MOURA, J.C.; DA SILVA, S.C.; DE FARIA, V.P. (Eds.) SIMPÓSIO SOBRE MANEJO DE PASTAGENS, 20., 2003, Piracicaba. Anais... Piracicaba: FEALQ, 2003. p. 155-186.

DA SILVA \& NASCIMENTO JR. Ecofisiologia de plantas forrageiras. In: PEREIRA, O.G.; OBEID, J.A.; NASCIMENTO Jr., D.; FONSECA, D.M. (Eds.). Simpósio sobre manejo estratégico da pastagem, III, Viçosa, 2006. Anais... Viçosa: UFV, 2006, p.1-42, 430p.

EUCLIDES, V.P.B. Valor alimentício de espécies forrageiras do gênero Panicum. In: PEIXOTO, A.M.; MOURA, J.C.; FARIA, V.P. (Eds.) Simpósio sobre manejo da pastagem, 12, Piracicaba, 1995. Anais... Piracicaba: FEALQ, 1995, p.245-274.

GOMIDE, J.A. Sistemas de manejo de gramíneas do gênero Melinis. In: PEIXOTO, A.M.; MOURA, J.C.; FARIA, V.P. (Eds.) Simpósio sobre manejo da pastagem, 9, Piracicaba, 1988. Anais... Piracicaba : FEALQ, 1988. p.41-56.

GONÇALVES, A.C. Características morfogêni-cas e padrões de desfolhação em pastos de capim-Marandu submetidos a regimes de lotação contínua. Dissertação (Mestrado em Agronomia - Ciência Animal e Pastagens) Escola Superior de Agricultura "Luiz de Queiroz", Piracicaba. 124p., 2002.

GONTIJO NETO, M.M.; EUCLIDES, V.P.B.; NASCIMENTO JR., D. et al. Consumo e tempo diário de pastejo por novilhos Nelore em pastagem de capim-tanzânia sob diferentes ofertas de forragem. Revista Brasileira de Zootecnia, v.35, n.1, p.60-66, 2006.

HACK, E. Variações estruturais e produção de leite na pastagem de capim-mombaça. Dissertação (Mestrado em Agronomia - Ciência Animal e Pastagens) - Universidade Federal do Paraná, Paraná. 48p., 2004.

HILLESHEIM, A. Manejo do gênero Pennisetum sob pastejo. In: PEIXOTO, A.M.; MOURA, J.C.; FARIA, V.P. (Eds.) SIMPÓSIO SOBRE MANEJO DA PASTAGEM, 9., 1998, Piracicaba. Anais... Piracicaba: FEALQ, 1988. p.77-108.

HODGSON, J. The influence of grazing pressure and stocking rate on herbage intake and animal perfomarnce. University College of Wales, Aberystwyth. In: HODGSON, J. \& D.K. JACKSON.(Eds.) OCCASIONAL SYMPOSIUM, 8., 1975, Aberystwyth. Anais... Brit. Grass. Soc. 1975. pp.93-103

HODGSON, J. Variations in the surface characteristics of the sward and short-term rate of herbage intake by calves and lambs. Grass and Forage Science, v.36, p.49-57, 1981.

HODGSON, J. The significance of sward characteristics in the management of temperate sown pastures. In: INTERNATIONAL GRASSLAND CONGRESS, 15., Kyoto, 1985. Proceedings... Nishi-Nasuno: Japanese Society of Grassland Science, 1985. p.63-67.

HODGSON, J. Grazing management-science into practice. Essex, England, Longman Scientific \& Technical, 1990. $203 p$.

HODGSON, J.; DA SILVA, S.C. Sustainability of grazing systems: goals, concepts and methods. In: LEMAIRE, G.; HODGSON, J.; MORAES, A.; CARVALHO, P.C.F.; NABINGER, C. (Eds.) Grassland ecophysiology and grazing ecology. CABI Publishing, CAB International, Wallingford, Oxon OX10 8DE, UK, 2000. p.1-14. 
JACQUES, A. Fisiologia do crescimento de Plantas Forrageiras. In: FARIA, V.P.; MOURA, J.C. (Eds.) SIMPÓSIO SOBRE MANEJO DA PASTAGEM, 1, PIRACICABA, 1973. Anais... Piracicaba : FEALQ, 1973, p.95-101.

JEWISS, O.R. Tillering in Grasses - its significance and control J. Brit. Grassld. Soc., v.27, p.65-82, 1972.

KORTE, C.J.; WATKIN, B.R.; HARRIS, W. Use of residual leaf area index and light interception as criteria for springgrazing management of a ryegrass-dominant pasture. New Zealand Journal of Agricultural Research, v.25, p.309319, 1982.

LEITE, G.G. Manejo de plantas forrageiras dos gêneros Andropogon, Hyparrhenia e Setaria. In: PEIXOTO, A.M.; MOURA, J.C.; FARIA, V.P. (Eds.) SIMPÓSIO SOBRE MANEJO DA PASTAGEM, 9, Piracicaba, 1988. Anais... Piracicaba : FEALQ, 1988. p.185-218.

LEITE, G.G.; EUCLIDES, V.B.P. Utilização de pastagens de Brachiaria spp. In: PEIXOTO, A.M.; MOURA, J.C.; FARIA V.P. (Eds.) SIMPÓSIO SOBRE MANEJO DAPASTA-GEM, 11, Piracicaba, 1994. Anais... Piracicaba: FEALQ, 1994 p.267-298.

LOPES, B.A. Características morfofisiológicas e acúmulo de forragem em capim-mombaça submetido a regimes de desfolhação. Tese (Doutorado em Zootecnia)Universidade Federal de Viçosa, Viçosa. 210p., 2006.

MARASCHIN, G.E. Pastejo rotacionado. In: PEIXOTO, A.M.; MOURA, J.C.; FARIA, V.P. (Eds.) SIMPÓSIO SOBRE MANEJO DA PASTAGEM, 3., 1976, Piracicaba. Anais... Piracicaba : FEALQ, 1976. p.253-282.

MARASCHIN, G.E. Manejo de plantas forrageiras dos gêneros Digitaria, Cynodon e Chloris. In: PEIXOTO, A.M.; MOURA, J.C.; FARIA, V.P. (Eds.) SIMPÓSIO SOBRE MANEJO DA PASTAGEM, 9., 1988, Piracicaba. Anais.. Piracicaba : FEALQ, 1988. p.109-140.

MARASCHIN, G.E. Oportunidade do uso de leguminosas em sistemas intensivos de produção animal a pasto. In: PEIXOTO, A.M.; MOURA, J.C.; FARIA V.P. (Eds.) SIMPÓSIO SOBRE MANEJO DA PASTAGEM, 14., 1997, Piracicaba. Anais... Piracicaba : FEALQ, 1997. p.139-160.

MARASCHIN, G.E. Relembrando o passado, entendendo o presente e planejando o futuro. Uma herança em forrageiras e um legado em pastagens. In: NASCIMENTO Jr. D.; LOPES, P.S.; PEREIRA, J.C. (Eds.) REUNIÃO ANUALDA SOCIEDADE BRASILEIRA DE ZOOTECNIA, 37., 2000, Viçosa. Anais... Viçosa : UFV, 2000. p.113-180.

MARASCHIN, G.E.; JACQUES, A.V.A. Grassland opportunities in the southern region of South América. In: BAKER, M.J. (Ed.) Grasslands for our world. WellingtonNZ:SIR Publishing. 1993. p.748-752.

MARTINICHEN, D. Efeito da estrutura do capim Mombaça sobre a produção de vacas leiteiras. Dissertação (Mestrado em Agronomia - Produção Vegetal) - Universidade Federal do Paraná, Curitiba. 64p., 2002.

MELLO, A.C.L.; PEDREIRA, C.G.S. Respostas morfológicas do capim-Tanzânia (Panicum maximum Jacq. cv. Tanzânia1) irrigado à intensidade de desfolha sob lotação rotacionada. Revista Brasileira de Zootecnia, v.33, n.2, p.282-289, 2004.

MOLAN, L.K. Estrutura do dossel, inter-ceptação luminosa e acúmulo de forragem em pastos de capim-marandu submetidos a alturas de pastejo por meio de lotação contínua. Dissertação (Mestrado em Agronomia - Ciência Animal e Pastagens) - Escola Superior de Agricultura "Luiz de Queiroz", Piracicaba. 159p., 2004.

MORAES, A.; MARASCHIN, G.E.; NABINGER, C. Pastagens nos ecossistemas de clima tropical: pesquisas para o desenvolvimento sustentável. In: REUNIÃO ANUAL DA SOCIEDADE BRASILEIRA DE ZOOTECNIA, 32., 1995, Brasília. Anais... Brasília: Sociedade Brasileira de Zootecnia, 1995. p.147.

MORENO, L.S.B. Produção de forragem de capins do gênero Panicum e modelagem de respostas produtivas e morfofisiológicas em função de variáveis climáticas. Dissertação (Mestrado em Ciência Animal e Pastagens)Escola Superior de Agricultura "Luiz de Queiroz", Piracicaba. 86p., 2004

MOTT, G.O. Grazing pressure and the measurement of pasture production. In: INTERNATIONAL GRASSLAND CONGRESS, 8., Reading, 1960. Proceedings... Bristish Grassland Association, 1960. p.606-611.

MOTT, G.O. Potential productivity of temperate and tropical grassland systems. In: SMITH, J.A.; HAYS, V.W. (Eds.) INTERNATIONAL GRASSLAND CONGRESS, 14., 1983, Lexington. Proceedings... Lexington: International Grassland Society. 1983. p.35-41.

NABINGER, C. Princípios da exploração intensiva de pastagens. In: PEIXOTO, A.M.; MOURA, J.C.; FARIA, V.P. (Eds.) SIMPÓSIO SOBRE MANEJO DA PASTAGEM, 13., 1996, Piracicaba. Anais... Piracicaba: FEALQ, 1996. p.15-96.

NABINGER, C. Disponiblidade e perdas de forragem. In: PEIXOTO, A.M.; MOURA, J.C.; FARIA, V.P. (Eds.) SIMPÓSIO SOBRE MANEJO DA PASTAGEM, 14, 1997, Piracicaba. Anais... Piracicaba: FEALQ, 1997. p.213-272.

NASCIMENTO Jr., D.; BARBOSA, R.B.; MARCELINO, K.R.A. et al. A produção animal em pastagens no Brasil: uso do conhecimento técnico e resultados. In: PEIXOTO, A.M.; MOURA, J.C.; Da SILVA, S.C.; De FARIA, V.P. (Eds.) SIMPÓSIO SOBRE MANEJO DA PASTAGEM, 20., 2003, Piracicaba. Anais... Piracicaba: FEALQ, 2003, p.1-82.

NASCIMENTO Jr., D.; DA SILVA, S.C.; ADESE, B. Perspectivas futuras do uso de gramíneas em pastejo. In: MEDEIROS, S.P.; EUCLIDES FILHO, K.; EUCLIDES, V.P.B.(Eds.) SIMPÓSIO SOBRE FORRAGEIRAS E PRODUÇÃO EM PASTAGENS, 41., 2004, Campo Grande. Reunião Anual da SBZ, 2004. Anais... Campo Grande: Embrapa Gado de Corte, 2004. p.130-141.

NASCIMENTO Jr., D.; GARCEZ NETO, A.F.; BARBOSA, R.A. et al. Fundamentos para o manejo de pastagens: evolução e atualidade. In: OBEID, J.A.; PEREIRA, O.G; FONSECA, D.M.; NASCIMENTO Jr., D. (Eds.). SIMPÓSIO SOBRE MANEJO ESTRATÉGICO DA PASTAGEM, 1., 2002, Viçosa. Anais... Viçosa: UFV, 2002. p.149-196.

PARSONS, A.J.; JOHNSON, I.R.; HARVEY, A. Use of a model to optimize the interaction between frequency and severity of intermittent defoliation to provide a fundamental comparison of the continuous and intermittent defoliation of grass. Grass and Forage Science. v.43, p.49-59, 1988.

PARSONS, A.J.; LEAFE, E.L.; COLLETT, B. et al. The physiology of grass production under grazing. II. Photosynthesis, crop growth and animal intake of continuously-grazed swards. Journal of Applied Ecology, v.20, p.127-139, 1983.

PARSONS, A.J.; PENNING, P.D. The effect of the duration of regrowth on photosynthesis, leaf death and the average rate of growth in a rotationally grazed sward. Grass and Forage Science, v.43, n.1, p.15-27, 1988.

PEDREIRA, B.C. Interceptação de luz, arquitetura e assimilação de carbono em dosséis de capim-xaraés [Brachiaria brizantha (A. Rich.) Stapf. cv. Xaraés] submetidos a estratégias de pastejo rotacionado. Dissertação (Mestrado em Agronomia - Ciência Animal e Pastagens)- Escola Superior de Agricultura "Luiz de Queiroz", Piracicaba. 86p., 2006.

PINTO, J.C.; GOMIDE, J.A.; MAESTRI, M. Produção de matéria seca e relação folha:caule de gramíneas forrageiras tropicais, cultivadas em vasos, com duas doses de Nitrogênio. Revista da Sociedade Brasileira de Zootecnia, v.23, n.3, p.313-326, 1994a.

PINTO J.C.; GOMIDE, J.A.; MAESTRI, M. Crescimento de folhas de gramíneas forrageiras tropicais, cultivadas em vasos, com duas doses de nitrogênio. Revista da Sociedade Brasileira de Zootecnia, v.23, n.3, p.327-332, 1994b.

(ㄷ) 2007 Sociedade Brasileira de Zootecnia 
RODRIGUES, L.R.A.; REIS, R.A. Bases para o estabelecimento do manejo de capins do gênero Panicum. In: PEIXOTO, A.M.; MOURA, J.C.; FARIA, V.P. (Eds.) SIMPÓSIO SOBRE MA-NEJO DA PASTAGEM, 12., 1995, Piracicaba. Anais... Piracicaba: FEALQ, 1995. p.197-218.

RODRIGUES, L.R.A.; RODRIGUES, J.D. Ecofisiologia de plantas forrageiras. In: CASTRO, P.R.C. et al. (Eds.) Ecofisiologia da produção agricola. Piracicaba: Assoc. Bras. Pesq. Da Potassa e do Fosfato, 1987. p.203-225.

SARMENTO, D.O.L. Comportamento ingestivo de bovinos em pastos de capim-marandu submetidos a regimes de lotação contínua. Dissertação (Mestrado em Ciência Animal e Pastagens) - Escola Superior de Agricultura "Luiz de Queiroz", Piracicaba. 76p., 2003.

SBRISSIA, A.F. Morfogênese, dinâmica do perfilhamento e do acúmulo de forragem em pastos de capim-Marandu sob lotação contínua. Tese (Doutorado em Ciência Animal e Pastagens) - Escola Superior de Agricultura "Luiz de Queiroz", Piracicaba. 171p., 2004.

SBRISSIA, A.F.; DA SILVA, S.C. O ecossistema de pastagens e a produção animal In: MATTOS, W.R.S.; FARIA, V.P.; DA SILVA, S.C.; NUSSIO, L.G.; MOURA, J.C. (Eds.) REUNIÃO ANUAL DA SOCIDADE BRASILEIRA DE ZOOTEC-NIA, 38., 2001, Piracicaba. Anais... Piracicaba: SBZ, 2001, p.731-754.

SILVA, A.L.P. Estrutura do dossel e o comportamento ingestivo de novilhas leiteiras em pastos de capim Mombaça. Tese (Doutorado em Agronomia) - Universidade Federal do Paraná, Setor de Ciências Agrárias, Curitiba. 104p., 2004.

SIMÃO NETO, M. Sistemas de pastejo. 2. In: PEIXOTO, A.M.; MOURA, J.C.; FARIA, V.P. (Eds.) SIMPÓSIO SOBRE MANEJO DA PASTAGEM, 8., 1986, Piracicaba. Anais... Piracicaba: FEALQ, 1986. p.291-307.

SMITH, D. Carbohydrate root reserves in alfalfa, red clover, and birdsfoot trefoil under management schedules. Crop Science, v.2, p.75-78, 1962.

STOBBS, T.H. The effect of plant structure on the intake of tropical pastures. 1. Variation in the bite size of grazing cattle. Australian Journal of Agricultural Research, v.24, p.809819, 1973a.

STOBBS, T.H. The effect of plant structure on the intake of tropical pastures. 2. Differences in sward structure, nutritive value, and bite size of animals grazing Setaria anceps and Chloris gayana at various stages of growth. Australian Journal of Agricultural Research, v.24, p.821-829, 1973b.

TRINDADE, J.K. Modificações na estrutura do pasto e no comportamento ingestivo de bovinos durante o rebaixamento do capim-marandu submetido a estratégias de pastejo rotacionado. Dissertação (Mestrado em Agronomia - Ciência Animal e Pastagens) - Escola Superior de Agricultura "Luiz de Queiroz", Piracicaba. 162p., 2007.

VOLENEC, J.J.; NELSON, C.J. Forage crop management: Applications of emerging technologies. In: HEATH, M.E.; METCALFE, D.S.; BARNES, R.F. (Eds.). Forages: The science of grassland agriculture, 3.ed. Vol. 1. Iowa, USA: The Iowa State University Press, 1995. p.3-20.

VOLTOLINI, T.V. Adequação protéica em rações com pastagens ou com cana-de-açúcar e efeito de diferentes intervalos entre desfolhas da pastagem de capim Elefante sobre o desempenho lactacional de vacas leiteiras. Tese (Doutorado em Ciência Animal e Pastagens) - Escola Superior de Agricultura "Luiz de Queiroz", Piracicaba. 167p., 2006.

WARREN WILSON, J. Influence of spatial arrangement of foliage area on light interception and pasture growth. In: INTERNATIONAL GRASSLAND CONGRESS, 8., Reading, 1960. Proceedings... British Gassland Association, 1960. p. 275-279.

XAVIER. E.A.; MARASCHIM, G.E.; HARTHMANN, O.M.L. et al. Oferta de Forragem de Capim-Elefante Anão 'Mott' e a Dinâmica da Pastagem. Revista Brasileira de Zootecnia, v.29, n.5, p.1281-1287, 2000.

WEINMANN, H. Total carbohydrates in grasses and legumes. Herb. Abstr., v.31, p.255-261, 1961.

ZEFERINO, C.V. Morfogênese e dinâmica do acúmulo de forragem em pastos de capim-marandu [Brachiaria brizantha (Hochst. ex A. Rich) cv. Marandu] submetidos a regimes de lotação intermitente por bovinos de corte. Dissertação (Mestrado em Ciência Animal e Pastagens)Escola Superior de Agricultura "Luiz de Queiroz”, Piracicaba. 193p., 2006.

ZIMMER, A.H.; EUCLIDES, V.B.P.; MACEDO, M.C.M. Manejo de plantas forrageiras do gênero Brachiaria. In: PEIXOTO, A.M.; MOURA, J.C.; FARIA, V.P. (Eds.) SIMPÓSIO SOBRE MA-NEJO DA PASTAGEM, 9., 1988, Piracicaba. Anais... Piracicaba:FEALQ, 1988. p.141-184. 